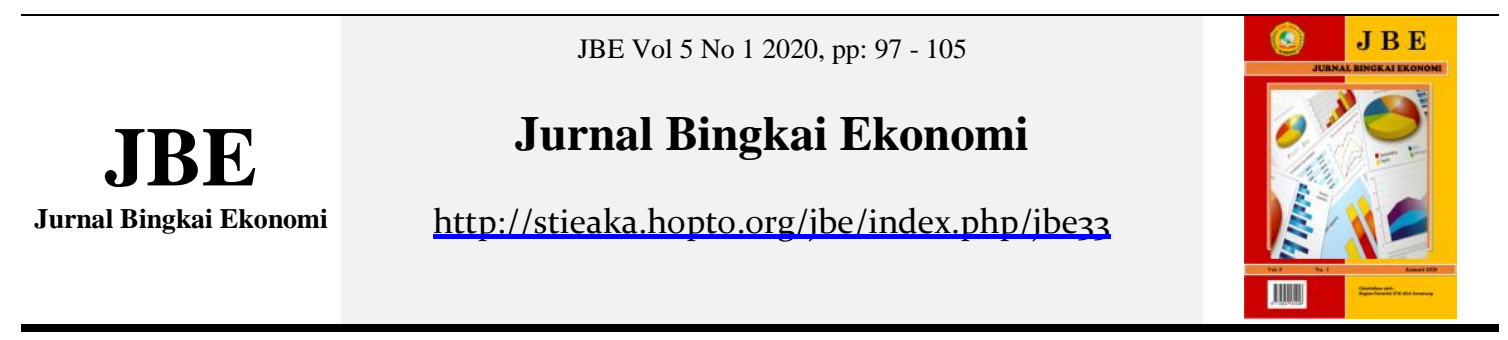

\title{
PENGARUH PENGAWASAN DAN LINGKUNGAN KERJA TERHADAP KINERJA KARYAWAN PADA PT EUDE INDONESIA
}

\author{
${ }^{1}$ Bambang Widjanarko Susilo \\ ${ }^{2}$ Yolanda Desitawati
}

${ }^{1}$ Dosen, Manajemen, STIE AKA Semarang, Semarang, Indonesia

${ }^{2}$ Mahasiswa, Manajemen, STIE AKA Semarang, Semarang, Indonesia

\section{Info Artikel}

\section{Sejarah Artikel:}

Diterima : 24 Februari 2020

Disetujui 26 Februari 2020

Dipublikasikan : 27 Februari 2020

Keywords:

Supervision ; work

environment ; employee

performance

\begin{abstract}
Abstrak
Tujuan penelitian ini untuk mengetahui seberapa besar pengaruh lingkungan kerja serta pengawasan terhadap kinerja karyawan pada PT EUDE Indonesia. Penelitian ini menggunakan pendekatan analisis kuantitatif.Populasi penelitian ini adalah karyawan PT EUDE Indonesia sebanyak 360 orang. Teknik pengambilan sampel $20 \%$ dari jumlah populasi yaitu sebanyak 72 orang. Analisis data menggunakan SPSS 22.0 diantaranya uji reliabilitas, uji validitas, uji regresi linier berganda, uji $F$, dan uji koefisien determinasi $\left(R^{2}\right)$. Hasil analisis menunjukkan Lingkungan Kerja dan Pengawasan secara bersamaan berpengaruh terhadap Kinerja Karyawan PT EUDE Indonesia. Hasil analisis uji koefisien determinasi $\mathrm{R}^{2}$ persentase dari pengaruh lingkungan kerja dan pengawasan terhadap kinerja karyawan adalah nilai adjusted R Square sebesar 29.2\% yang sisanya 70.8\% dipengaruhi faktor lain yang tidak diteliti.

Kata kunci : Pengawasan ; Lingkungan Kerja ; Kinerja Karyawan.
\end{abstract}

The purpose of this study was to determine how much influence the supervision and work environment have on employee performance at PT EUDE Indonesia. This study uses a quantitative analysis approach.The population in this study were PT EUDE Indonesia employees totaling 360 people. The sampling technique is $20 \%$ of the total population of 72 people. Data analysis using SPSS 25.0 includes coefficient of determination (R2), $F$ test,reliability, multiple linear regression and validity. The results showed that and Work Environment and Supervision simultaneously influence the Employee Performance of PT EUDE Indonesia. Based on the results of the coefficient of determination $R^{2}$ percentage of the effect of supervision and work environment on employee performance can be seen from the adjusted $R$ Square value of $29.2 \%$ with the remaining $70.8 \%$ affected by other factors not examined.

Keywords: supervision ; work environment ; employee performance 


\section{PENDAHULUAN}

Persaingan dunia bisnis yang semakin keras mengharuskan instansi perusahaan untuk meningkatkan kinerja karyawan. Dalam menciptakan suatu barang jasa dan produk jasa yang dibutuhkan konsumen diperlukan tenaga kerja dengan skill kemampuan bekerja dan semangat kerja yang tinggi.Selain itu kinerja karyawan erat hubungannya dengan tujuan perusahaan.

Efek kinerja karyawan dalam perusahaan baik maka tujuan perusahaan akan tercapai dengan baik dan sebaliknya apabila kinerja karyawan rendah maka dalam mencapai tujuan perusahaan tersebut akan mengalami kesulitan. Efek kinerja karyawan dipengaruhi oleh beberapa faktor, diantaranya adalah lingkungan kerja dan pengawasan.

Lingkungan kerja dan pengawasan erat hubungannya dengan kinerja karyawan terutama dalam penyelesaian tugas.Apabila suatu perusahaan ingin mencapai tujuan yang diinginkan maka perusahaan perlu meningkatkan kinerja karyawan. Dengan kondisi kinerja karyawan yang baik adalah kondisi pencapaian suatu perusahaan itu mengelola sumber daya manusianya.

Kinerja sebagai output atau keluaran yang dihasilkan oleh fungsi-fungsi atau indikator-indikator pekerjaan atau profesi dalam waktu tertentu (Wirawan, 2009:5). Kinerja karyawan tersebut dapat dilihat dari hasil kerjanya. Output hasil kerja karyawan dapat dibaca dan diketahui pihak pimpinan dalam hal kemampuan dan kecakapan pegawainya. Oleh dari itu untuk dapat mengukur maka perusahaan menggunakan standar-standar yang tinggi dalam proses penerimaan karyawan. Lingkungan organisasi sebagai suatu kondisi yang tak terhingga ( Ismail, 2009:146). Selain lingkungan kerja yang perlu diperhatikan, peran pengawasan merupakan faktor penting untuk proses peningkatan kinerja karyawan. Dengan perusahaan melakukan pengawasan displin keras maka dapat diketahui tingkat kerja kinerja karyawan. Menurut Sadili (2010:299) "mendefinisikan Pengawasan sumber daya manusia sebagai kegiatan manajemen dalam mengadakan pengamatan terhadap kulitas sumber daya manusia yang dimiliki dan yang ada di pasaran tenaga kerja”. Sehingga dengan adanya pengawasan diharapkan seluruh pihak dalam organisasi atau perusahaan dapat meningkatkan produktifitas yang tinggi untuk pencapaian kinerja pegawai much better menjadi lebih baik dengan penilaian obyektif dalam penetapan target kinerja serta masukan-masukan. PT EUDE Indonesia adalah suatu perusahaan bergerak di bidang industri pengolahan kayu dan tembaga dengan produk yang terkait dengan kapal pesiar dan mebel khusus untuk kapal. Hal ini menuntut perusahaan untuk benar-benar melakukan berbagai bentuk kegiatan efisiensi pada perusahaan tanpa melanggar peraturan yang telah ditetapkan oleh pemerintah. Dengan ketatnya peraturan pemerintah bagi perusahaan yang bergerak dibidang pengolahan kayu, dan semakin banyak perusahaan yang bergerak dibidang yang sama terutama perusahaan dari Cina, membuat pelanggan lebih banyak memiliki pilihan produk. Dari harga yang 
mahal hingga murah dan menjanjikan pelayanan purna jual yang baik bagi pelanggan, penanganan keluhan yang cepat dan didukung oleh tim yang profesional dan kreatif serta ahli dalam bidangnya. Inilah yang dilakukan oleh PT EUDE Indonesia, dengan memberikan produk yang terbaik bagi pelanggan untuk mendapatkan kepercayaan menjadi prioritas perusahaan.

Rumusan masalah :

1.Apakah pengawasan berpengaruh terhadap kinerja karyawan?

2.Apakah lingkungan kerja berpengaruh terhadap terhadap kinerja karyawan ?

\section{TINJAUAN PUSTAKA}

\section{Pengawasan}

Pengawasan sebagai salah satu fungsi manajemen dalam pencapaian tujuan, memegang peranan yang sangat penting karena dengan adanya pengawasan kemungkinan terjadinya penyimpangan dapat dicegah, sehingga usaha untuk mengadakan perbaikan atau koreksi dapat segera dilakukan. Pengawasan adalah proses pengamatan dari pelaksanaan kinerja seluruh kegiatan organisasi untuk menjamin agar semua pekerjaan yang sedang di lakukan berjalan sesuai dengan rencana yang telah di tentukan ( Siagian,2014:213) dan pengawasan menurut ( Siagian, 2014:35) itu terdiri dari kontrol masukan, kontrol perilaku dan kontrol keluaran.

\section{Lingkungan Kerja}

Keadaan lingkungan kerja yang baik akan memberikan dampak yang positif bagi seseorang dalam meningkatkan kinerjanya. Hal itu merupakan salah satu cara yang dapat ditempuh agar seseorang dapat melaksanakan tugasnya tanpa mengalami gangguan, karena lingkungan kerja sangat mempengaruhi kinerja. Indikator lingkungan kerja dari Wursanto dalam Dharmawan (2011:47), adalah suasana kerja seperti kekeluargaan ditempat kerja, perlakuan yang baik seperti perlakuan yang baik dan adil antara sesama rekan kerja dan atasan, rasa aman seperti mendapatkan perlindungan dari ancaman kecelakaan menggunakan fasilitas instansi serta hubungan yang harmonis seperti komunikasi antara sesama rekan kerja dan atasan.

\section{Kinerja Karyawan}

Kinerja adalah hasil kerja yang dapat dicapai oleh seseorang atau sekelompok orang dalam suatu organisasi, sesuai dengan wewenang dan tanggung jawab masing-masing dalam upaya mencapai tujuan organisasi bersangkutan secara legal, tidak melanggar hukum dan sesuai dengan moral maupun etika.

Kinerja karyawan bukan hanya merupakan hasil kerja yang dicapai seseorang dalam melaksanakan tugastugas yang dibebankan kepadanya tetapi juga termasuk disiplin kerja karyawan dan prilaku kerja karyawan. Dimensi kinerja karyawan dari Sedarmayanti (2013:377) adalah kesetiaan, kemampuan, kejujuran, kerjasama, ketaatan, prakarsa dan tanggung jawab. 
Kerangka Teoritis

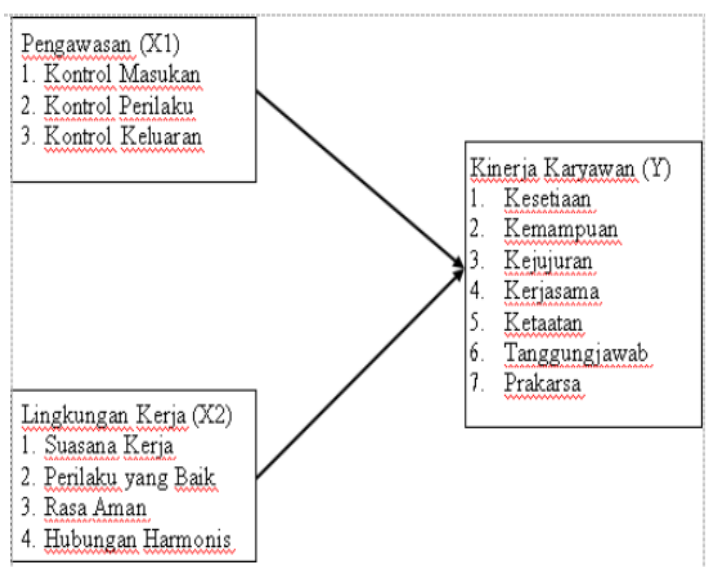

Hipotesis dalam penelitian ini

H1: Diduga pengaruh positif dan signifikan pengawasan terhadap kinerja karyawan

H2: Diduga pengaruh posifit dan signifikan lingkungan kerja terhadap kinerja karyawan

Pengaruh positif dan signifikan lingkungan kerja terhadap kinerja karyawan.

Pengawasan juga mempengaruhi kinerja pegawai pada perusahaan atau organisasi untuk meningkatkan atau memperbaiki kinerja perusahaan melalui evaluasi kinerja. Menurut Mangkunegara (2011:69) bahwa sebagai dasar untuk mengevaluasi metode kerja maka dibutuhkan suatu pengawasan untuk memperoleh kinerja yang efektif dan efisien, hal ini sejalan dengan penelitian Tri (2012) yang menyatakan bahwa terdapat pengaruh positif dan signifikan pengawasan terhadap kinerja karyawan.

\section{Pengaruh positif dan signifikan lingkungan kerja terhadap kinerja karyawan.}

Kondisi lingkungan dapat mempengaruhi kinerja pegawai seperti yang dikemukakan Robbins (2010:36), bahwa para pegawai menaruh perhatian yang besar terhadap lingkungan kerja mereka, baik dari segi kenyamanan pribadi maupun kemudahan melakukan pekerjaan dengan baik, hal ini sejalan dengan penelitian Tri (2012) yang menyatakan bahwa pengaruh positif dan signifikan lingkungan kerja terhadap kinerja karyawan.

\section{METODOLOGI PENELITIAN}

\section{Populasi dan Sampel}

Populasi dalam penelitian ini adalah seluruh karyawan PT Eude Indonesia. Sedangkan sampel dalam penelitian ini diambil dengan teknik sampling yang nonprobability sampling dengan teknik purposive sampling.

Menurut Sugiyono (2016:85) bahwa: "purposive sampling adalah teknik pengambilan sampel sumber data dengan pertimbangan tertentu."Alasan menggunakan teknik Purposive Sampling adalah karena tidak semua sampel memiliki kriteria yang sesuai dengan fenomena yang diteliti. Oleh karena itu, penulis memilih teknik Purposive Sampling yang menetapkan pertimbanganpertimbangan atau kriteria-kriteria tertentu yang harus dipenuhi oleh sampel-sampel yang digunakan dalam penelitian ini.

Dalam penelitian ini yang menjadi sampel yaitu karyawan yang memenuhi kriteria tertentu. Adapun kriteria yang dijadikan sebagai sampel penelitian yaitu:

1. Masih aktif bekerja di PT EUDE Indonesia

2. Mempunyai absensi mendekati $100 \%$ 
PEMBAHASAN

\section{Uji Validitas}

\begin{tabular}{|c|c|c|c|c|}
\hline Variabel & Indikator & $\mathrm{r}_{\text {lïmg }}$ & $\mathrm{r}_{\text {talle }}$ & Keterangan \\
\hline \multirow{3}{*}{ Pengawasan } & $\mathrm{X} 1.1$ & 0,488 & \multirow{14}{*}{0,232} & Valid \\
\hline & $\mathrm{X} 1.2$ & 0,881 & & Valid \\
\hline & $\mathrm{X} 1.3$ & 0,843 & & Valid \\
\hline \multirow{4}{*}{$\begin{array}{c}\text { Lingkungan } \\
\text { Kerja }\end{array}$} & $\mathrm{X} 2.1$ & 0,633 & & Valid \\
\hline & $\mathrm{X} 2.2$ & 0,818 & & Valid \\
\hline & $\mathrm{X} 2.3$ & 0,804 & & Valid \\
\hline & $\mathrm{X} 2.4$ & 0,786 & & Valid \\
\hline \multirow{7}{*}{$\begin{array}{c}\text { Kinerja } \\
\text { Karyawan }\end{array}$} & $\mathrm{Y} 1.1$ & 0,702 & & Valid \\
\hline & $\mathrm{Y} 1.2$ & 0,825 & & Valid \\
\hline & $\mathrm{Y} 1.3$ & 0,812 & & Valid \\
\hline & $\mathrm{Y} 1.4$ & 0,751 & & Valid \\
\hline & $\mathrm{Y} 1.5$ & 0,719 & & Valid \\
\hline & $\mathrm{Y} 1.6$ & 0,798 & & Valid \\
\hline & $\mathrm{Y} 1.7$ & 0,490 & & Valid \\
\hline
\end{tabular}

Sumber : data diolah, 2019

Berdasarkan tabel validitas, dapat dilihat bahwa nilai $r$ hitung lebih kecil dari $r$ tabel maka dapat dikatakan bahwa variabel pengawasan , lingkungan kerja dan kinerja karyawan adalah valid.

\section{Uji Reliabilitas}

\begin{tabular}{|l|c|c|l|}
\hline \multicolumn{1}{|c|}{ Variabel } & $\begin{array}{c}\text { Cronbach's } \\
\text { Alpha }\end{array}$ & $\begin{array}{c}\text { Standard } \\
\text { Alpha }\end{array}$ & Keterangan \\
\hline Pengawasan & 0,613 & 0,60 & Reliabel \\
\hline Lingkungan Kerja & 0,748 & 0,60 & Reliabel \\
\hline Kinerja Karyawan & 0,841 & 0,60 & Reliabel \\
\hline
\end{tabular}

Sumber : data diolah, 2019

Hasil uji reliabilitas tersebut menunjukan bahwa semua variabel mempunyai koefisien alpha $>0,6$ sehingga dapat dikatakan bahwa semua konsep alat ukur masing masing variabel dari kuesioner adalah reliabel sehingga untuk selanjutnya item-item pada masing masing konsep variabel tersebut layak digunakan sebagai alat ukur (Ghozali, 2011:133).
Analisis Regresi Berganda

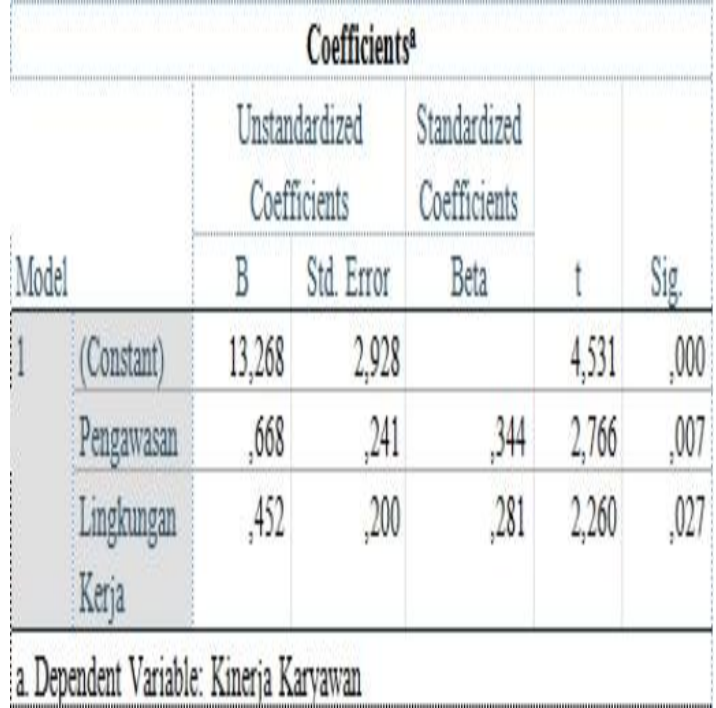

Sumber : Data yang diolah (2019)

Berdasarkan tabel coefficient, maka diperoleh persamaan regresi sebagia berikut :

$$
\begin{aligned}
& Y=a+b_{1} X_{1}+b_{2} X_{2} \\
& Y=13,268+0,344 X_{1}+0,281 X_{2}
\end{aligned}
$$

Dimana :

$\mathrm{Y}=$ Variabel Kinerja Karyawan

$\mathrm{X} 1=$ Variabel Pengawasan

$\mathrm{X} 2=$ Variabel Lingkungan Kerja

$\beta 1=$ Koefisien regresi variabel Pengawasan

$\beta 2=$ Koefisien regresi variabel Lingkungan Kerja

Berdasarkan persamaan diatas diperoleh hasil konstanta sebesar 13,268, artinya jika variabel lingkungan kerja dan pengawasan sama dengan nol maka besarnya kinerja karyawan adalah 13,268. Nilai koefisien variabel Pengawasan (X1) mempunyai pengaruh yang postif terhadap kinerja karyawan sebesar 0,668. Hal ini berarti bahwa setiap kenaikan 1 satuan dari variabel pengawasan, maka variabel kinerja karyawan akan meningkat sebesar 0.668.Begitu juga sebaliknya jika pengawasan menurun maka kinerja karyawan akan ikut menurun. Koefisien 
variabel Lingkungan Kerja (X2) mempunyai pengaruh yang positif terhadap kinerja karyawan sebesar 0,452. Hal ini berarti bahwa setiap kenaikan 1 satuan dari variabel lingkungan kerja, maka variabel kinerja karyawan akan meningkat. Begitu juga sebaliknya jika lingkungan kerja menurun maka kinerja karyawan akan ikut menurun.

\section{UJI F ANOVA ${ }^{a}$}

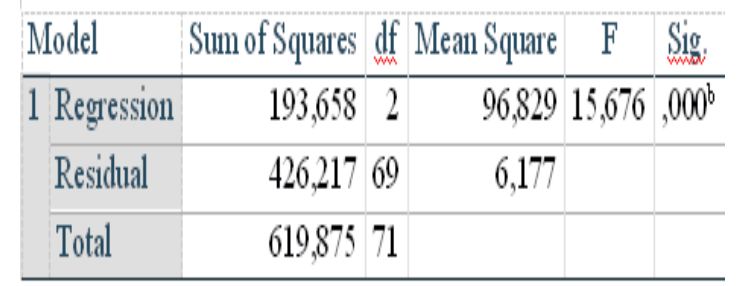

Dependent Variable: Kinerja Karyawan

Predictors: (Constant),

Pengawasan, lingkungan kerja

Sumber : data yang diolah (2019)

Berdasarkan tabel hasil uji $\mathrm{F}$ diperoleh Fhitung sebesar 15,676, selanjutnya dibandingkan dengan nilai Ftabel yaitu dfl $=\mathrm{k}-1$ dan df $2=\mathrm{n}-\mathrm{k}$ dimana $\mathrm{n}$ yaitu sampel (72) dan k yaitu banyaknya variabel bebas atau independen (2), maka nilai $F_{\text {tabel }}$ diperoleh sebesar 3,98 dengan tingkat signifikansi 0,05. Dengan membandingkan nilai $F_{\text {hitung }}$ sebesar $15,676>F_{\text {tabel }}$ sebesar 3,98 dan nilai signifikasi sebesar $0,000<$ 0,05 maka Ho ditolak dan Ha di terima, sehingga dapat dinyatakan variabel lingkungan kerja dan pengawasan berpengaruh yang signifikan secara simultan atau bersama-sama terhadap kinerja karyawan.

\begin{tabular}{|c|c|c|c|c|}
\hline \multicolumn{5}{|c|}{$\begin{array}{l}\text { Hasil Uji Koefisien Determinasi }\left(\mathbf{R}^{2}\right) \\
\text { Model Summary }\end{array}$} \\
\hline Model & $\mathrm{R}$ & R Square & $\begin{array}{l}\text { Adjusted R } \\
\text { Square }\end{array}$ & $\begin{array}{l}\text { Std. Error of the } \\
\text { Estimate }\end{array}$ \\
\hline 1 &, $559^{3}$ &, 312 &, 292 & 2,48 \\
\hline
\end{tabular}

Sumber : data diolah,2019

Predictors : (Constant), Pengawasan,
Lingkungan Kerja

Berdasarkan tabel hasil uji koefisien determinasi diperoleh angka AdjustedR Square sebesar 0,292 atau (29,2\%). Hal ini menunjukkan bahwa persentase kemampuan menjelaskan lingkungan kerja dan pengawasan terhadap kinerja karyawan di PT EUDE Indonesia sebesar $29,2 \%$. Dengan kata lain variabel kinerja karyawan dapat dipengaruhi oleh variabel lingkungan kerja dan pengawasan sebesar 29,2\%, sedangkan sisanya $70,8 \%$ dipengaruhi oleh variabel lain yang tidak diteliti.

\section{Pengawasan berpengaruh positif dan signifikan terhadap kinerja karyawan}

Pengawasan memegang peranan penting dalam meningkatkan kinerja karyawan.Apabila suatu perusahaan mengadakan pengawasan maka dapat diketahui tingkat kerja kinerja karyawan. Sehingga dengan adanya pengawasan diharapkan seluruh pihak dalam organisasi atau perusahaan dapat meningkatkan produktifitas yang tinggi. Selain itu pengawasan kerja juga berguna dalam mencapai kinerja pegawai yang lebih baik dengan memberikan dasar yang objektif bagi penetapan target kinerja dan memberikan masukan Sadili (2010). Hasil penelitian ini sejalan dengan Indriasih ( 2016 ) yang menyatakan bahwa pengawasan berpengaruh terhadap kinerja karyawan.

\section{Lingkungan kerja berpengaruh positif dan signifikan terhadap kinerja karyawan}

Lingkungan kerja merupakan segala sesuatu yang ada di sekitar pegawai baik fisik maupun non fisik yang 
mempengaruhi pegawai pada saat bekerja seperti suasana kerja, hubungan yang harmonis baik itu antara sesama rekan kerja maupun atasan dan pengaruh lingkungan yang bisa mempengaruhi pegawai dan kinerja pegawai tersebut Wursanto (2011). Hasil penelitian ini sejalan dengan Indriasih ( 2016 ) yang menyatakan bahwa lingkungan kerja berpengaruh terhadap kinerja karyawan.

\section{Kesimpulan}

Berdasar hasil penelitian dan pembahasan mengenai pengaruh pengawasan dan lingkungan kerja terhadap kinerja karyawan PT Eude Indonesia, maka dapat disimpulkan bahwa :

1. Pengawasan berpengaruh positif dan signifikan terhadap kinerja karyawan PT Eude Indonesia. Semakin meningkatnya pengawasan akan semakin meningkat pula kinerja karyawannya.

2. Lingkungan kerja berpengaruh posifit dan signifikan terhadap kinerja karyawan PT Eude Indonesia. Semakin kondisi lingkungan kerja meningkat, akan semakin pula meningkat kinerja karyawannya.

\section{Saran}

Berdasarkan hasil dan pembahasan penelitian, maka saran yang dapat diberikan sebagai berikut :

1. Atasan PT EUDE Indonesia diharapkan dapat menerapkan pengawasan yang lebih baik dengan menciptakan mekanisme pengawasan yang lebih ketat dan dapat dipantau dengan mudah sehingga secara otomatis munculnya atau timbulnya penyimpangan / penyelewengan dapat dilihat dengan segera yang bertujuan untuk meningkatkan kualitas pengawasan terhadap peningkatan kinerja karyawan.

2. Atasan PT EUDE Indonesia diharapkan dapat selalu mengontrol dan membandingkan antara pelaksanaan kerja dengan standar kerja yang telah ditetapkan dengan menerapkan program kerja yang terorganisir.

3. Bagi penelitian selanjutnya dengan tema sejenis, diharapkan dapat menggunakan alat ukur yang lebih baik dan menggunakan variabel lain yang lebih banyak agar dapat mencapai titik penelitian yang optimal.

\section{Keterbatasan Penelitian}

Penelitian ini telah diusahakan dan dilaksanakan sesuai dengan prosedur ilmiah, namun demikian masih memiliki keterbatasan yaitu :

1. Faktor-faktor yang mempengaruhi Kinerja Karyawan dalam penelitian ini hanya terdiri dari dua variabel, yaitu Pengawasan dan Lingkungan Kerja, sedangkan masih banyak faktor lain yang mempengaruhi Kinerja Karyawan.

2. Adanya keterbatasan penelitian dengan menggunakan kuesioner yaitu terkadang jawaban yang diberikan oleh responden tidak menunjukkan keadaan sesungguhnya.

\section{Rekomendasi Peneliti Yang Akan Datang \\ Peneliti selanjutnya dapat mengembangkan penelitian ini dengan}


meneliti faktor lain yang dapat mempengaruhi kinerja karyawan karena faktor dalam penelitian ini hanya menggunakan 2 variabel saja yaitu pengawasan dan lingkungan kerja, sehingga masih ada faktor-faktor lain yang mempengaruhi kinerja karyawan selain variabel yang diteliti. Peneliti selanjutnya dapat menganalisis faktor yang dapat meningkatkan kinerja karyawan misalnya disiplin, motivasi, kompensansi dan lainlain

\section{DAFTAR PUSTAKA}

Prabu, AA. 2011. Manajemen Sumber Daya Manusia Perusahaan. PT Remaja Rosda Karya. Bandung

Kuncoro, A., 2011. Cara Menggunakan dan Memakai Analisis Asumsi Klasik, Cetakan Pertama, Alfabeta, Bandung.

Arikanto, S., 2007. Prosedur Penelitian Suatu Pendekatan Praktek. Edisi Revisi VI hal 134. Rineka Apta, Jakarta.

Ferdinand, A., 2006. Metode Penelitian Manajemen: Pedoman Penelitian Untuk Skripsi, Tesis dan Disertasi Ilmu Manajemen. Universitas Diponegoro, Semarang.

Bawono, A., 2006. Multivariate Analysis Dengan SPSS, STAIN Salatiga Press., Salatiga.

Daft. R.L., 2012. Manajemen Edisi 1. Alih Bahasa Edward Tanujaya dan Shirley Tiolina, Salemba Empat, Jakarta.

Indriasih, D. dan Rosdiana, D. 2016. Pengaruh Lingkungan Kerja, Kompetensi dan Motivasi Terhadap Kinerja Dengan Variabel Kompensansi Sebagai Variabel Intervening Pada Pegawai Dishubkominfo Kota Tegal. Jurnal
Politeknik Kesehatan Transportasi, 1:1, 2016, 57-65

Dharmawan, 2011. Lingkungan Kerja Fisik dan Non Fisik. PT Remaja Rosdakarya, Bandung.

Fitria, M.M., dan Utami, D., 2015. Analisis Pengawasan Kompetensi Melalui Kerja Terhadap Kepuasan Kerja Karyawan Pada PT East West Seed Indonesia. Jurnal Teknologi Pertanian,vol 16, no 2, Agustus 2015, 97-106.

Ghozali, I., 2006. Aplikasi Analisis Multivariate Dengan Program SPSS edisi 4. Badan Penerbit Universitas Diponegoro, Semarang.

Hair, J.F., 1998. Multivariate Data Analysis,Fifth Edition. Prentice Hall, USA

Handoko, H., 2011. Manajemen Personalia dan Sumber Daya Manusia. Penerbit BPFE, Yogyakarta

Hasibuan, M., 2011. Manajemen Sumber Daya Manusia. Bumi Aksara, Jakarta.

Imron, A., 2012. Manajemen Peserta Didik Berbasis Sekolah, Bumi Aksara, Jakarta.

Istijanto, 2005. Aplikasi Praktis Riset Pemasaran. PT Gramedia Pustaka Utama, Jakarta.

Matis, dan Jakson, R.L, 2010. Manajemen Sumber Daya Manusia. Penerjemah Jimmy Sadeli dan Batu Prawira. Penerbit PT Salemba Empat, Jakarta

Moekijat, 2010. Sumber Daya Manusia. CV Mandar Maju, Bandung.

Nanawi, I., 2011. Manajemen Sumber Daya Manusia: Untuk Bisnis yang Kompetitif. Gajah Mada University Press, Yogyakarta.

Rivai, 2011. Manajemen Sumber Daya Manusia Untuk Perusahaan dari Teori Ke Praktek, Raja Grafindo, Jakarta. 
Robbins, S., 2010. Manajemen Edisi Ke Sepuluh. Penerbit Erlangga, Surabaya.

Samsudin, S., 2010. Manajemen Sumber Daya Manusia. Pustaka Setia, Bandung.

Sedarmayanti, 2013. Manajemen Sumber Daya Manusia. Refika Aditama, Bandung.

Siagian, S., 2014. ManajemenSumber Daya Manusia. Bumi Aksara, Jakarta

Sugiyono. 2016. Metode Penelitian (Pendekatan Kuantitatif, Kualitatif dan R\&D). Alfabet. Bandung.

Sukarna, 2011. Dasar-Dasar Manajemen. CV Mandar Maju, Bandung.

Suwanto, 2011. Manajamen Sumber Daya Manusia Dalam Organisasi Publik dan Bisnis. Alfabeta, Jakarta.

Wibowo, 2011. Manajemen Kinerja. PT Raja Grafindo Persada, Jakarta

Winardi, 2009. Kepemimpinnan Di Dalam Manajemen, PT. Rineka Cipta, Jakarta.

Wirawan, 2009. Evaluasi Kinerja Sumber Daya Manusia Teori Aplikasi dan Penelitian. Penerbit: Salemba Empat, Jakarta

Wursanto, 2011. Dasar-Dasar Ilmu Organisasi. Andi Offset. Yogyakarta

Wursanto, 2011. Dasar-dasar Ilmu Organisasi. Andi Offset. Yogyakarta 